\title{
The Prevalence of HIV in Cancer Patients at the Surgical Oncology Unit of Donka University Hospital of Conakry (Guinea)
}

\author{
Bangaly Traore, ${ }^{1}$ Thierno Souleymane Bah, ${ }^{2}$ Fode Amara Traore, ${ }^{2}$ \\ Mamadou Saliou Sow, ${ }^{2}$ Solomana Diane, ${ }^{1}$ Mamady Keita, ${ }^{1}$ Mohamed Cisse, ${ }^{3}$ \\ Moussa Koulibaly, ${ }^{4}$ and Naby Daouda Camara ${ }^{5}$ \\ ${ }^{1}$ Surgical Oncology Unit, Donka University Hospital, Conakry, Guinea \\ ${ }^{2}$ Infectious and Tropical Disease Department, Donka University Hospital, Conakry, Guinea \\ ${ }^{3}$ Department of Dermatology and Venereology, Donka University Hospital, Conakry, Guinea \\ ${ }^{4}$ Department of Pathology, Donka University Hospital, Conakry, Guinea \\ ${ }^{5}$ Department of General Surgery, University Hospital of Conakry, Guinea
}

Correspondence should be addressed to Bangaly Traore; ucodonka@gmail.com

Received 23 September 2015; Revised 8 November 2015; Accepted 19 November 2015

Academic Editor: Subhojit Dey

Copyright (C) 2015 Bangaly Traore et al. This is an open access article distributed under the Creative Commons Attribution License, which permits unrestricted use, distribution, and reproduction in any medium, provided the original work is properly cited.

\begin{abstract}
Aim. To determine the prevalence of HIV infection among patients seen at the surgical oncology unit of Donka (Conakry, Guinea). Method. We conducted a retrospective and descriptive study of HIV infection in cancer patients from May 2007 to December 2012. Social characteristics (age, gender, marital status, and education) and immune status (HIV type, CD4 count) were reviewed. Results. Out of 2598 cancer patients, 54 (2.1\%) tested positive for HIV. There were 11 (20.4\%) defining AIDS and 43 (79.6\%) nondefining AIDS cancers. The most frequent cancers were breast (14) (26.0\%), non-Hodgkin lymphoma (6) (11.1\%), liver (6) (11.1\%), eye and annexes (6) (11.1\%), and cervical cancer (5) (9.3\%). These patients were female in $34(63.0 \%)$ and had a median age of 39 years and body mass index was $20,3 \mathrm{Kg} / \mathrm{m}^{2}$. They were unschooled in $40(74.1 \%)$ and married in $35(64.8 \%)$. CD4 count showed a median of 317 cells/mL. Antiretroviral treatment was performed in 40 (74.1\%). Conclusion. HIV prevalence is higher in patients in our unit of surgical oncology. Breast cancer was the most common in this association. A national survey of a large sample is needed to determine the true prevalence and impact of HIV on cancer prognosis.
\end{abstract}

\section{Background}

While opportunistic infections continue to be enameled care of patients infected with acquired immunodeficiency, cancer remains overlooked in the care of these patients in developing countries.

According to Center Disease Control (CDC) [1], the revised definition of AIDS criteria includes the biological criteria (CD4 below 200) and/or clinical criteria (opportunistic infections, cancers of the cervix, Kaposi sarcoma, and nonHodgkin lymphoma) associated with infection by human immunodeficiency virus (HIV).
The occurrence of malignant tumors in patients with HIV infection currently represents for years to come one of the most difficult and controversial challenges of therapeutic management of these patients [2]. As of 2011, 69\% of all people infected with HIV live in sub-Saharan Africa. Africa was the epicenter of viral related cancers even prior to the HIV epidemic (e.g., Kaposi's sarcoma (KS), Burkitt's lymphoma, cervical cancer, and hepatocellular carcinoma).

Indeed, 30 to $40 \%$ of patients infected with HIV are likely to develop cancer about their disease [3]; the incidence of certain cancers such as Kaposi's sarcoma has decreased since the introduction of potent antiretroviral therapies; other 
malignancies associated with AIDS do not seem to be affected by the establishment of this new therapeutic strategy [4]. The prevalence coinfection TB/HIV (25.5\%) is well known while no study on cancers associated with HIV has been performed in our country [5].

The widespread use of antiretroviral therapy (ARV) in industrialized countries since the mid-1990s led to a dramatic decrease in mortality of patients with HIV infection and incidence of opportunistic infections [6].

However, antiretroviral treatment types HAART also had a significant impact on the natural history of HIV-associated malignancies [7].

A US study found an increase in median survival of AIDS patients from 11.3 months before 1985 to 12.5 months in 1986 to 20.8 months in 1987 for AIDS cases diagnosed in Washington [8]. According to a recent British study, $40 \%$ of AIDS patients have cancer during the course of their disease [9].

In France, a study showed that, out of a total of 964 recorded deaths, 149 were attributed to the type of AIDS defining cancers [7].

According to the Regional Office for Africa of WHO, 64\% of new cancer cases worldwide are registered in developing countries [10].

Sub-Saharan African countries have experienced nearly 600,000 deaths in 2008 related to tumors. If this epidemiological trend continues due to longer life expectancy and increased exposure to tobacco, Africa will have by 2020 from 800,000 to $1,000,000$ new cases of cancer each year $[10,11]$.

The cancer incidence rate is estimated at 95.5 cases per $10^{5}$ inhabitants in West Africa and 90.0 per $10^{5}$ in Guinea [12]. As in most sub-Saharan African countries, the cancer is often diagnosed at an advanced stage of the disease.

There is very little data available on the prevalence of HIV infection in cancer patients in West Africa, especially in our country. It is therefore important to have a first database that will guide future investigations.

This study aims to determine the prevalence of HIV infection among patients seen at the surgical oncology unit of Donka.

\section{Material and Method}

2.1. Data. Data from this study were obtained from the hospital and came from surgical oncology unit of Donka national hospital, teaching hospital of Conakry (Guinea).

The study involved the records of cancer patients followed with HIV infection from May 2007 to December 2012.

2.2. HIV and Immune Status. The status of HIV infection was determined by the Western blot method. This checkup has become routine for any cancer patient received in our unit since January 2009.

CD4 count was requested for HIV positive patients.

All patients were referred to antiretroviral treatment center for treatment of immune status.
2.3. Data Collection. The prevalence has been determined according to the number of patients and pathology subject of consultation or follow-up. Pathologies associated with HIV have been classified into malignant, benign, and inflammatory diseases.

Social characteristics (age, gender, marital status, tobacco and alcohol consumption, education, and body mass index) and immune status (HIV type, CD4 count, and antiretroviral treatment) were reviewed according malignant tumor pathologies, divided into defining AIDS and nondefining AIDS cancers. Gynecological history (age at menarche, first full pregnancy) was determined in women with breast cancer.

2.4. Statistical Analysis. This was descriptive and retrospective study. The qualitative variables were presented and analyzed in percentage. The median with interquartile range (IQR) was calculated for the quantitative variables. Defining AIDS and nondefining AIDS cancers were compared in relation to patient age. ANNOVA test was performed and was significant if $p$ was less than 0.05 .

\section{Results}

Out of 3143 patients received from May 2007 to December 2012, 69 (2.2\%) tested positive for HIV in our unit. This proportion was $12(1.9 \%)$ of 625 patients from 2007 to 2008 and 57 (2.3\%) of 2518 patients from 2009 to 2012 .

Of the $64 \mathrm{HIV}$-infected patients, $54(78.3 \%)$ had a malignant tumor, $8(11.6 \%)$ of benign and $7(10.1 \%)$ of inflammatory tumors (Table 1).

The prevalence of HIV in cancer patients was 54 on 2598 cases $(2.1 \%)$. Of the 54 cases of cancers associated with $\mathrm{HIV}$, there were 11 (20.4\%) defining AIDS and 43 (79.6\%) nondefining AIDS.

These patients were female in $34(63.0 \%)$. Cancer patients had a median age of 39 (IQR 31-48) against 32 (IQR 25-38) for noncancer patients. This median age was different about defining AIDS status: 33 (25.0-40.0) versus 39 (IQR 35.750.0) $(p=0.007)$.

Their body mass index was $20,4 \mathrm{Kg} / \mathrm{m}^{2}$ (IQR $17.7-21.8$ ). They were unschooled in $40(74.1 \%)$ and married in 35 $(64.8 \%)$. Tobacco use was found in $13(24.1 \%)$ and alcohol consumption in $14(20.2 \%)$.

All patients were infected with HIV type 1. CD4 count, performed in 22 patients, showed a median of 317 cells $/ \mathrm{mL}$ (IQR 246.2-534.2). Antiretroviral treatment was performed in $40(74.1 \%)$ patients of which it was performed in 39 only after the cancer diagnosis.

Table 2 shows the distribution of different types of cancers depending on the AIDS definition. Among the cancers defining AIDS, non-Hodgkin's lymphoma (6) (11.1\%) and cervical cancer (5) (9.3\%) were the most common.

Breast cancer (6) (11.1\%), followed by cancer of the liver (6) (11.1\%), and eye and annexes (6) (11.1\%) were leading nondefining AIDS cancers.

Patients with breast cancer had a median age of 14.0 years (IQR 12.5-15.0) at menarche and 22.0 years (IQR 17.0-25.0) in 
TABLE 1: Distribution of HIV patients according to associated diseases.

\begin{tabular}{lcccc}
\hline Primary sites & $\begin{array}{c}\text { Malignant } \\
\text { tumors }\end{array}$ & $\begin{array}{c}\text { Associated diseases } \\
\text { tumors }\end{array}$ & $\begin{array}{c}\text { Inflammatory } \\
\text { tumors }\end{array}$ & All \\
& $n(\%)$ & $n(\%)$ & $n(\%)$ & $n(\%)$ \\
\hline Breast & $14(20.3)$ & $2(2.9)$ & $1(1.4)$ & $17(24.6)$ \\
Node & $6(8.7)^{*}$ & $2(2.9)$ & $4(5.8)$ & $12(17.4)$ \\
Liver & $6(8.7)$ & - & - & $6(8.7)$ \\
Cervix uteri & $5(7.2)$ & $1(1.4)$ & $2(2.9)$ & $8(11.5)$ \\
Eyes & $4(5.8)$ & $2(2.8)$ & - & $5(7.2)$ \\
Skin & $4(5.8)$ & - & - & $4(5.8)$ \\
Soft tissues & $3(4.3)$ & - & - & $3(4.3)$ \\
Eyelids & $2(2.9)$ & - & - & $2(2.9)$ \\
Lung & $2(2.9)$ & - & - & $2(2.9)$ \\
Colon & $2(2.9)$ & - & - & $2(2.9)$ \\
Pancreas & $1(1.4)$ & - & - & $1(1.4)$ \\
Bone & $1(1.4)$ & - & - & $1(1.4)$ \\
Bladder & $1(1.4)$ & - & - & $1(1.4)$ \\
Larynx & $1(1.4)$ & - & - & $1(1.4)$ \\
Kidney & - & $1(1.4)$ & - & $1(1.4)$ \\
Unknown & $2(2.8)$ & - & - & $2(2.9)$ \\
All & $\mathbf{5 4}(\mathbf{7 8 . 3 )}$ & $\mathbf{8 ( \mathbf { 1 1 . 6 } )}$ & $\mathbf{7 ( 1 0 . 1 )}$ & $\mathbf{6 9}(\mathbf{1 0 0})$ \\
\hline
\end{tabular}

${ }^{*}$ Non-Hodgkin lymphoma.

TABLE 2: Distribution of cancer type to the SOU during the study period.

\begin{tabular}{lcc}
\hline Cancer types & Number & $\%$ \\
\hline Defining AIDS & 6 & \\
Non-Hodgkin lymphoma & 5 & 11,1 \\
Cervical cancer & 1 & 9,3 \\
Kaposi sarcoma & & 1,9 \\
Nondefining AIDS & 14 & \\
Breast & 6 & 25,9 \\
Liver & 6 & 11,1 \\
Eyes and adnexa & 4 & 11,1 \\
Skin (carcinoma and melanoma) & 2 & 7,4 \\
Soft tissues & 2 & 3,7 \\
Lung & 2 & 3,7 \\
Colon & 1 & 3,7 \\
Bladder & 1 & 1,9 \\
Pancreas & 1 & 1,9 \\
Bone & 1 & 1,9 \\
Ovary & 1 & 1,9 \\
Larynx & 1 & 1,9 \\
Unknown & 54 & 1,9 \\
All & & 100 \\
\hline
\end{tabular}

the first full term pregnancy; and they had 1.0 full pregnancy in term (IQR 0.5-3.0).

\section{Discussion}

This preliminary study shows a high prevalence (2.1\%) of the HIV infection in patients with cancer in our surgical oncology unit. This prevalence appeared to be higher than in the general population in Guinea (1.5\%) [13] but lower than in the tertiary hospital (6.0\%) in Nigeria [14].

Inversely, 30-40\% of those HIV-infected patients are at risk of cancer [15]. Risk of cancer occurrence in HIV-infected people is 6.39 times higher compared to uninfected HIV people [16].

In this study, non-AIDS defining cancers were more frequent than defining AIDS cancers (77.8\% versus 22.2\%). This could be explained partly by the decrease in the number of cancer cases defining AIDS since the beginning of antiretroviral therapy as supported by Yanik et al. in the US [17]. Also, Kaposi's sarcoma (KS) and cervical cancer are mainly managed, respectively, by the dermatology and gynecology departments of teaching hospital. Kaposi's sarcoma is very common in dermatology and the Guinean first data were published by Cisse et al. [18]. In Nigeria, KS and cervical cancer are the most common cancers among non-AIDS defining cancers [19]. Cervical cancer is the most common cancer in Guinea with a high prevalence of human papillomavirus infection [20]. In this study, NHL was leading defining AIDS cancer. This high prevalence of NHL was reported in United States [16].

Breast cancer is the most common of nondefining AIDS cancers. This predominance of breast cancer among nondefining AIDS cancers is reported by studies in sub-Saharan Africa [21, 22]. The HIV infection is very prevalent, about $35.4 \%$ among women with breast cancer in Uganda [21] and $19.7 \%$ in South Africa [22]. In developed countries, lung cancer is the most common of nondefining AIDS cancers $[16,23]$.

We noted a female predominance and patients were younger. However, cancer patients were older than those who did not have cancer. Conversely, those with AIDS classifying cancer were younger than those who had a nonAIDS defining illness cancer. The female gender and the young age of patients are already reported by several authors $[14,21]$. Unschooling for most patients shows that they are from families with limited resources.

This study has some limitations related to the CD4 count and ART coverage. This could be related to the irregular availability of reagents for CD4 and antiretroviral despite their free access in our country. CD4 count, carried out for 22 cases out of 54, showed no difference in the depth of immunosuppression that cancer is either AIDS defining or not. For defining AIDS cancers, there is no doubt that the risk is higher in the case of lower CD 4 count $(<200$ cells $/ \mathrm{mL})[24$, 25]. However, there are controversies with regard to the depth of immunosuppression in nondefining AIDS cancer [22, 23, $25]$. We consider that the ART coverage rate (74.1\%) is low in this category of the population infected with HIV, although this rate is higher than the rate of coverage in Guinea (50.0\%) [26]. These patients are faced with two problems: HIV/AIDS with the supported opportunistic infections and cancer that is not supported by the national program against AIDS. 
That is why a national prospective study is needed to determine the true prevalence of cancer among people living with HIV. It will also be important to determine whether HIV changes the risk factors, clinicopathological futures, and prognosis of these cancers.

\section{Conclusion}

HIV prevalence is higher in patients in our unit of surgical oncology. Breast cancer is the most common in this association. A national survey of a large sample is needed to determine the true prevalence and impact of HIV on cancer prognosis.

\section{Conflict of Interests}

The authors declare that there is no conflict of interests regarding the publication of this paper.

\section{Authors' Contribution}

All authors have contributed substantially to the research or content of the paper.

\section{References}

[1] Centers for Disease Control and Prevention (CDC), "Revised surveillance case definition for HIV infection-United States, 2014," MMWR. Recommendations and Reports, vol. 63, no. 3, pp. 1-10, 2014.

[2] J. P. Spano, "Malignancies associated with HIV infection," La Lettre du Cancérologue, vol. 9, no. 5, pp. 203-217, 2000.

[3] M. Spina, E. Vaccher, A. Carbone, and U. Tirelli, "Neoplastic complications of VIH infection," Annals of Oncology, vol. 10, no. 11, pp. 1271-1286, 1999.

[4] M. Kaposi, "Idiopathisches multiples pigment Sarcoma der Haut," Archives of Dermatological Research, vol. 4, article 26, 1872.

[5] WHO, Cooperation Strategy-Health and Development, http:// www.who.int/countryfocus/cooperation_strategy/ccsbrief_gin _ fr.pdf.

[6] F. J. Jr. Palella, K. M. Delaney, A. C. Moorman et al., "Declining morbidity and mortality among patients with advanced human immunodeficiency virus infection. HIV Outpatient Study Investigators," The New England Journal of Medicine, vol. 338, no. 13, pp. 853-860, 1998.

[7] J. P. Spano and S. N. Faivre, "Non-AIDS-related malignancies: prognostic and treatment," Bulletin du Cancer, vol. 90, no. 5, pp. 413-418, 2003.

[8] W. E. Lafferty, D. Glidden, and S. G. Hopkins, "Survival trends of people with AIDS in Washington State," American Journal of Public Health, vol. 81, no. 2, pp. 217-219, 1991.

[9] B. S. Peters, E. J. Beck, D. G. Coleman et al., "Changing disease patterns in patients with AIDS in a referral centre in the United Kingdom: the changing face of AIDS," British Medical Journal, vol. 302, no. 6770, pp. 203-207, 1991.

[10] M. Ly, A. Ly, M. Rodrigues, D. Diallo, and M. Deberne, "Le cancer en Afrique, un nouveau défi sanitaire. Exemples du Mali et de l'association OncoMali," Bulletin du Cancer, vol. 97, no. 8, pp. 965-968, 2010.
[11] P. Kanavos, "The rising burden of cancer in the developing world," Annals of Oncology, vol. 17, no. 8, pp. viiil5-viii23, 2006.

[12] Globocan 2012, "Estmated cancer incidence, mortality and prevalence worldwide," 2014, http://globocan.iarc.fr/Default .aspx.

[13] Report UNGASD Guinea 2012, http://www.unaids.org/sites/ default/files/en/dataanalysis/knowyourresponse/countryprogressreports/2012countries/ce_GN_Narrative_Report[1].pdf.

[14] S. Ocheni and Y. A. Aken'Ova, "Association between HIV/AIDS and malignancies in a Nigerian tertiary institution," West African Journal of Medicine, vol. 23, no. 2, pp. 151-155, 2004.

[15] A. Ly, "Du VIH/sida aux tumeurs malignes associées," African Journal of Cancer, vol. 1, no. 3, pp. 123-126, 2009.

[16] R. M. Phelps, D. K. Smith, C. M. Heilig et al., "Cancer incidence in women with or at risk for HIV," International Journal of Cancer, vol. 94, no. 5, pp. 753-757, 2001.

[17] E. L. Yanik, K. Tamburro, J. J. Eron, B. Damania, S. Napravnik, and D. P. Dittmer, "Recent cancer incidence trends in an observational clinical cohort of HIV-infected patients in the US, 2000 to 2011," Infectious Agents and Cancer, vol. 8, no. 1, article $18,2013$.

[18] M. Cisse, T. S. Diallo, A. Kaba et al., "Maladie de Kaposi associée à l'infection par VIH,” Guinée Médicale, vol. 38, pp. 40-42, 2002.

[19] S. N. Akarolo-Anthony, L. D. Maso, F. Igbinoba, S. M. Mbulaiteye, and C. A. Adebamowo, "Cancer burden among HIVpositive persons in Nigeria: preliminary findings from the Nigerian AIDS-cancer match study," Infectious Agents and Cancer, vol. 9, no. 1, article 1, 2014.

[20] N. Keita, G. M. Clifford, M. Koulibaly et al., "HPV infection in women with and without cervical cancer in Conakry, Guinea," British Journal of Cancer, vol. 101, no. 1, pp. 202-208, 2009.

[21] J. Sseggwanyi, "Prevalence of HIV/AIDS among breast cancer patients and the clinico-pathological presentation of breast cancer with HIV/AIDS in Mulago Hospital," Makerere University Institional Repository School of Medicine Collection, 2011, http://makir.mak.ac.ug/handle/10570/2989.

[22] H. Cubasch, M. Joffe, R. Hanisch et al., "Breast cancer characteristics and HIV among 1,092 women in Soweto, South Africa," Breast Cancer Research and Treatment, vol. 140, no. 1, pp. 177186, 2013.

[23] M. R. Pinzone, F. Fiorica, M. Di Rosa et al., "Non-AIDSdefining cancers among HIV-infected people," European Review for Medical and Pharmacological Sciences, vol. 16, no. 10, pp. 1377-1388, 2012.

[24] M. Ulrickson, O. W. Press, and C. Casper, "Epidemiology, diagnosis, and treatment of HIV-associated non-hodgkin lymphoma in resource-limited settings," Advances in Hematology, vol. 2012, Article ID 932658, 7 pages, 2012.

[25] E. Lanoy, J.-P. Spano, F. Bonnet et al., "The spectrum of malignancies in HIV-infected patients in 2006 in France: the ONCOVIH study," International Journal of Cancer, vol. 129, no. 2, pp. 467-475, 2011.

[26] Solthis, HIV/AIDS in Guinea, September 2015, http://www.solthis.org/fr/pays-dintervention/guinee/contexte-et-objectifs. html. 


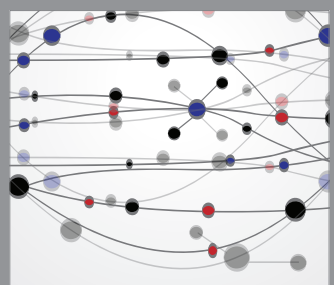

The Scientific World Journal
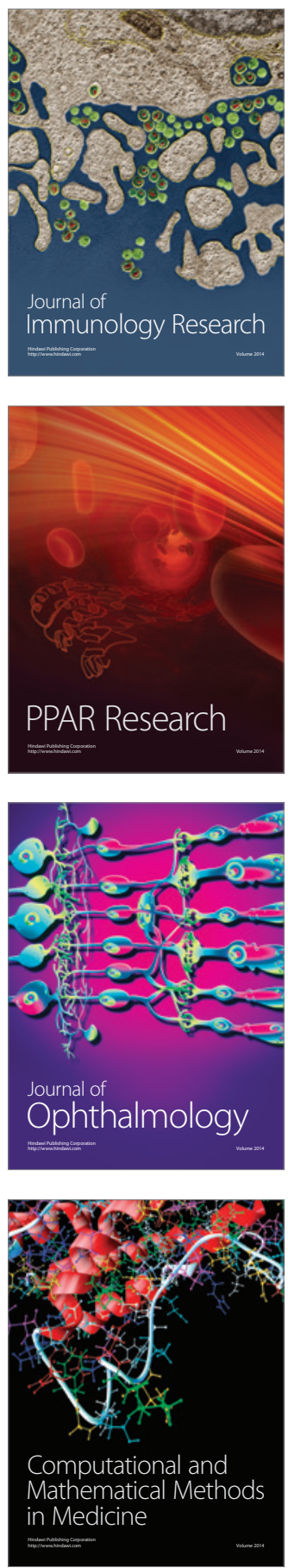

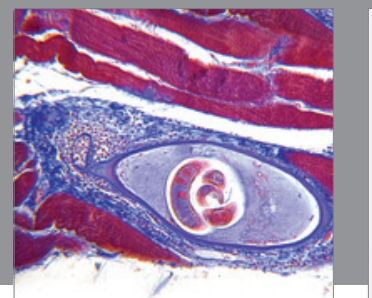

Gastroenterology

Research and Practice
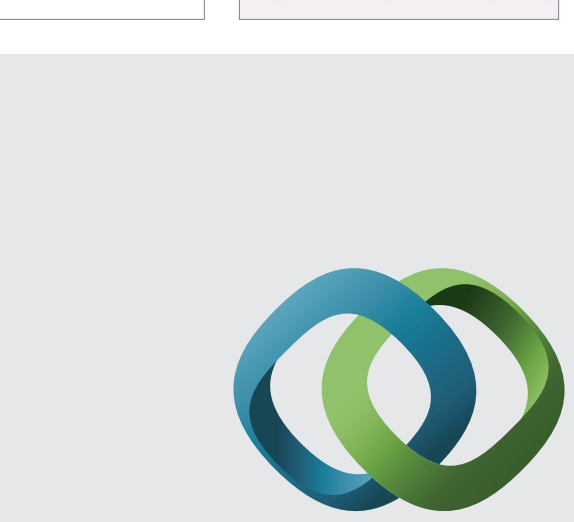

\section{Hindawi}

Submit your manuscripts at

http://www.hindawi.com
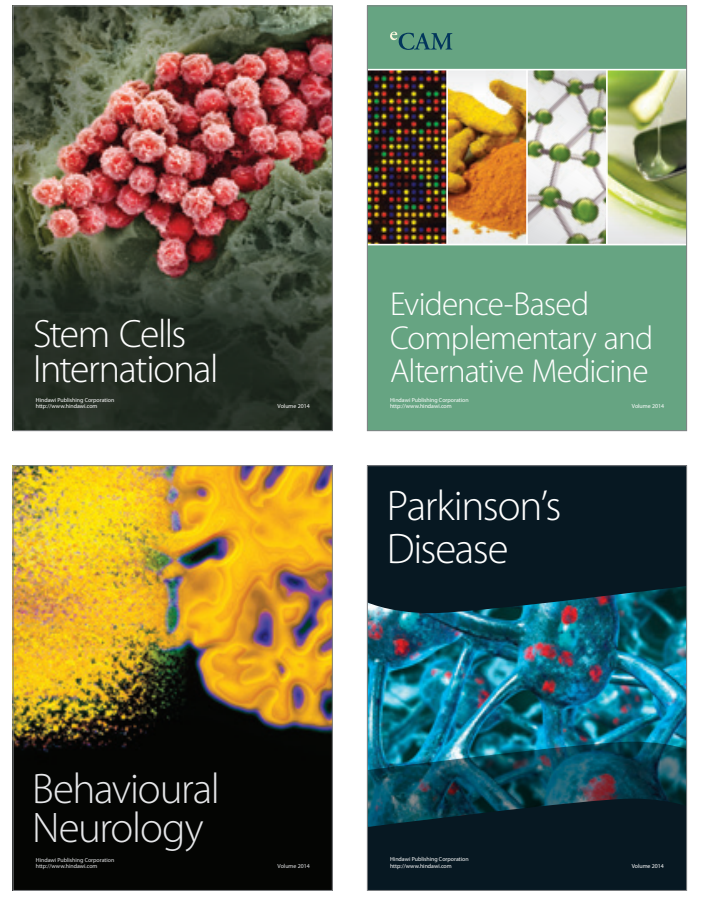
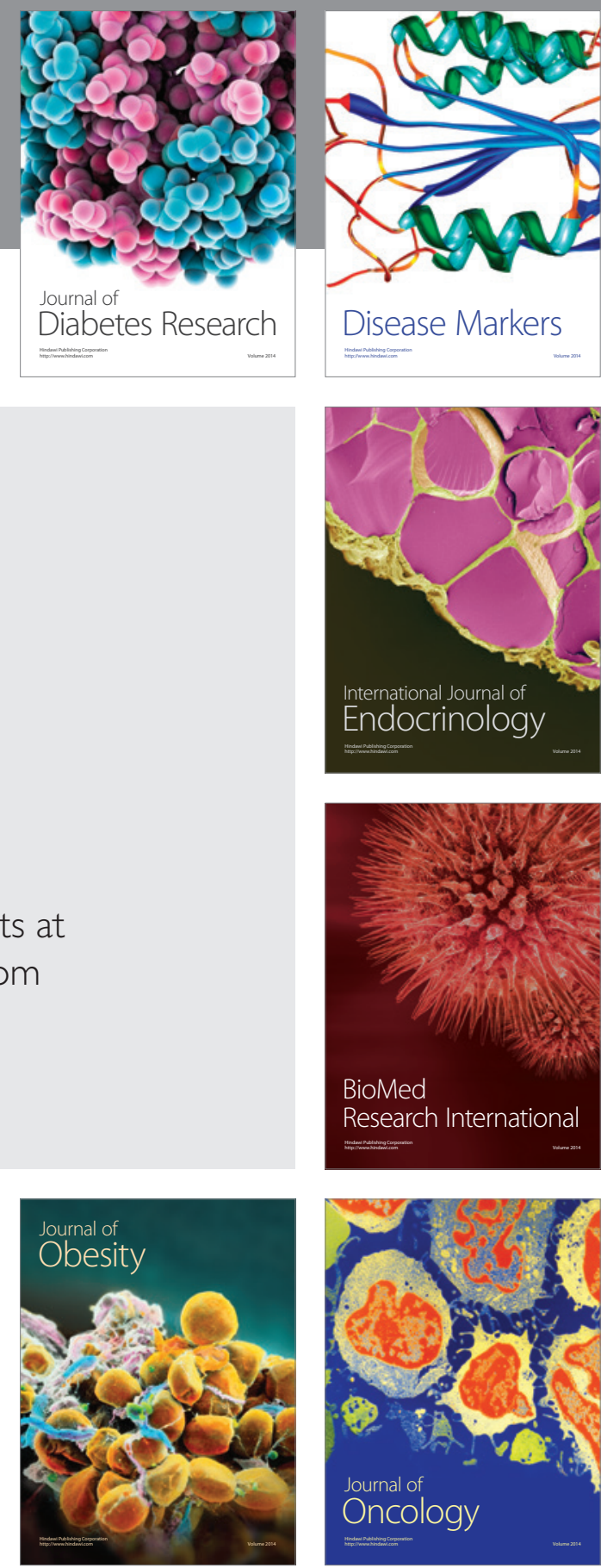

Disease Markers
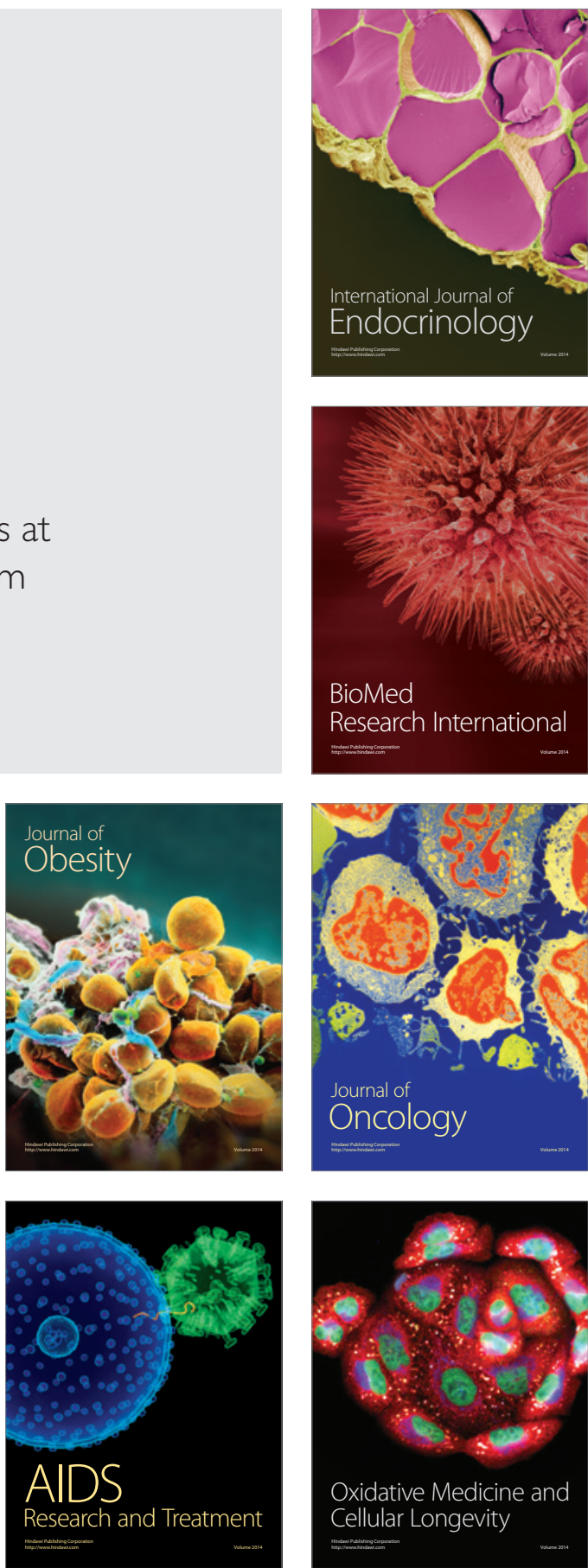